\title{
El Indigenismo Peruano y "El Padre Horan" de Narciso Aréstegui
}

\author{
Por Augusto tamayo Vargas
}

La literatura indigenista peruana tiene dos fuentes primigenias: la prosa de Garcilaso y la poesía de Melgar. Del primero recoge su penetrante mirada en los elementos nativos de nuestra personalidad nacional, aunque peque de tímida - $\mathrm{y}$ por otra parte natural-complacencia por lós elementos foráneos que plasmaron cruelmente en la conquista nuestra sociedad mestiza. Del segundo, arranca una manera propia que había venido elaborándose popularmente en la mezcla de elementos quechuas y castellanos y que encuentra su cauce en el "yaravi"; pero también en las elegías donde se cuela una sintaxis heterodoxa que habla de influencias quechuas I Ycenelasi "fábulas"t donde Melgar, utilizando las moralidades neoclásicas hace dg detensa, del indio dentro de la sociedad peruana.

Con esos dos grandes antecedentes, la literatura peruana del siglo XIX encuentra en la novela el camino del indigenismo, a través de un escritor cusqueño que rompe la línea del costumbrismo limeñista, para ofrecer en "El Padre Horón" una muestra diferente de la presentación literaria de costumbres. En efecto, Narciso Aréstegui -dejado a un lado por la crítica en general- hizo en aquella obra una verdadera revolución, presentando crudamente -cuarenta años antes del "realismo" peruano- una realidad viva y desconsoladora, con el cuadro de nuestra sociedad en que destaca la servidumbre aún imperante y el desajuste de la organización política y económica.

"El Padre Horán" es una novela indigenista y no indianista como muchas otras del romanticismo creciente a la fecha de su publicación: 1848. Los románticos tomaron al indio para la narración y la poesía colorista y exótica; para amores con "blancas" 
- viceversa; para mostrarnos tipos ideales de personajes americanos como los soñara Colón ante su visión inicial de las "indias occidentales'. La novela indianista del brasileño Alencar; del ecuatoriano León Mera, del dominicano Galván -aunque éste tomara algo del "indigenismo" del P. Las Casas- representan un mundo de fantasía y de ilusión, visto desde fuera, de "idealización" del indio como motivo poético en el que se recrea también Gonzálvez Díaz recogiendo la tradición épica de Ercilla.

En tanto Narciso Aréstegui iba a ofrecer dentro del carácter del indigenismo un cuadro del sector andino peruano con todas las miserias, las pobrezas, el encadenamiento social del indio. Por otra parte, la prepotencia caudillesca y al frente la actitud idolátrica de la masa, aún dominada por un sentimienio mágico - como puede verse en el capítulo del "crucifijo" llevado a Bolivia por las fuerzas de Santa Cruz- y la triste condición de las industrias familiares tradicionales para el indio y mestizo peruanos. Por , ello no puede pasarse tan en alto - como lo siguen haciendo los críticos-a esa novela inicial del indigenismo que después de cuarenta años fuera seguida por Itolararres y por Clorinda Matto, . tomando los mismos elementos que dejara ya establecidos Aréstegui: sociedad desajustada, indios explotados, malos sacerdotes, educación inadecuada, inescrupulosa casta dirigente, etc. Concretamente Itolararres llama. a su obra La Trinidad del Indio, "costumbres del interior", y los tres básicos problemas de la Matto: a) protesta por la condicíńngdel indion y poblemáa deda aldea andina: Aves Sin Nido; b) el mal sacerdote: Indole c) el problema sexual y la educación, Herencia, previamente considerados por Aréstegui en su novela de juventud, muestran una continuidad evidente.

Claro que no vamos a pensar que "El Padre Horán" es un lo- : gro literario. Es sí un magnífico esfuerzo, un documento importante y una base fundamental en la literatura indigenista peruana. Pero baste eso para registrarla como el más importante aporte producido en el siglo XIX para la obtención de una novela nuestra, que reflejara la condición indígenista. Sólo que "El Padre Horán" por su audacia, por su realismo desacostumbrado, que tal vez él mismo repudiara después, dentro de una actitud más conservadora, estuvo condenado al silencio y mirado prejuiciosamente como extraña obra inmoral y como elemento digno de figurar solamente en los anales judiciales. Nosotros hemos tratado de re- 
lievar su importancia, desde que publicamos en la revista "Turismo" un estudio sobre esa novela, en 1945, sacando a relucir su originalidad, su detalle minucioso, su franqueza revolucionaria, el empeño acucioso, que allí se observa, de mostrar la recilidad misma de los primeros años de la República del Perú.

"El Padre Horán" fue publicado en folletín en "El Comercio" de Lima, en 1848. Su autor -Narciso Aréstegui- fue un escritor cusqueño, nacido alrededor de 1820. Contaba pues ventitantos años cuando dio a conocer su obra que llevaba por subtítulo "Escenas de la vida del Cusco", y cuyo motivo central era el hecho verídico del asesinato de Angela Barreda por su ex-confesor Fray Eugenio Oros, realizado en 1836, según consta en el expediente criminal que se inserta en la edición que publicara en 1918 "El Comercio" del Cusco, con prólogo de A. Vega Enríquez.

Al lado de ese tema, en una presentación de escenas, costumbres y personajes características del Cusco, se desenvuelven varias historias: la historia del avaro; la historia de la mujer abandonada, cuyo marido murió peleando por la causa de la Emancipación; la historia - también cierta- del colegial que se suicida en la puerta del Colegio de Artes, porque su padre lo abofetea en público; y, lo que es más interesante, la historia de la pobreza, de la miseria de la población cusqueña. Recuerdos de Provincia, como los de Flaubert, pero no para la monotonía acompasada del "no hacer nada.' lde la mujeg del boticarion sino para la acumulación de intrigas y de tragedias lugareñas Parece como que el autor de "El Padre Horán" conociera ya el mundo de individualidades en lucha que presenta Balzac, quien por otra parte ya había comenzado su "Comedia Humana" con "Eugenia Grandet" en 1833, "El tío Goriot" en 1834, "La prima Bette" en 1847. Sus escenas de la vida privada, de la vida política, de la vida campestre, de las costumbres en general, es muy posible que hubieran llegado ya a conocimiento de Aréstegui, incitándolo a una investigación de la sociedad cusqueña. Pero el tema pasional del Padre Horán, tiene también antecedentes románticos en personajes de George Sand o de Víctor Hugo, contemporáneos de nuestro escritor. Y nuestras imperfecciones, nuestra anarquía política, las defi. ciencias de nuestra democracia formal que se imprimen allí, habían sido ya señaladas por la sátira de Felipe Pardo y Aliaga y por el relato exagerado y pasional de Flora Tristán, cuyo libro en francés "Peregrinaciones de una Paria" había sido quemado públicamente en Arequipa. 
El motivo central de la obra, o sea la pasión del Padre Horán por una muchacha de quince años, se manifiesta con un realismo verdaderamente extraño dentro de nuestra sociedad conservadora.

"- ¡Oh! ¡Bríjida -exclamó el franciscano, cuyos ojos relampaguearon en la oscuridad de aquel recinto. alma...

- iSi supieras... si pudieras imajinar lo que pasa en $\mathrm{mi}$

"-Mi buena hermana; escuchad las palabras del apóstol San Pablo, antes de oir mi opinión, fundada también en ellas. "Los que no tienen el don de continencia, cásense: porque más vale casarse que abrazarse".

La escena aumenta en crudeza cuando el Padre Horán pretende a Angélica, salvada por el Padre Lucas, reverso de la medalla del Padre Horán; constraste marcado para especificar que Ha obra no es anticlerical, si no que presentan simple y llanamente la sensualidad que no escoje para cobijarse determinado tipo o profesión de hombres. El mundo interior de El Padre Horán tiene frecuentes crisis, a través del lento deslizarse de la obra y culmina en el asesinato de Angélica.

La historia del avaro don Tadeo está también llena de truculencias y exageraciones retóricas. El avaro delira constantemente entre el recuerdo de lós crimenes cometidos por el afán de lucro y la inquietud de perdertos tespres adquiridos:erso"

“-No: no quiero... ¡Ah!... ¡qué calor... me circula poro todo el cuerpo! ¡No hary remedio... voy a morir!... ja morir! .. Hasta en mis sueños me persigue este recuerdo fatal. ¿Dónde podré huir de mi mismo?... ¡No quiero! ... Antolín... itengo miedo a la muerte!

Esta última palabra se ahogó como un grito de agonía en la garganta de don Tadeo, que se espeluznó todo. Antolín murmuró:

-Parece un gato que se defiende del perro..."

Casimira, humilde mujer del pueblo, cuyo marido cayó en la Pampa de Junín, vive tuberculosa en una especie de covacha y muere en el antihigiénico y desolado hospital de entonces.

1 Se sigue a través de las citas la ortografía del original. 
Wenceslao el estudiante del Colegio de Artes ama a Doloritas, la muchacha sin padres, humilde vendedora de guantes, motivo de atracción en las calles adormiladas del Cusco.

El padre de Wenceslao apostrofa y castiga a éste en la puerta del Colegio, por aquellos amores y una nueva desgracia se enlaza a las otras a través de esta serie de episodios fatales que Aréstegui considera lógicas conclusiones de la sociedad que se le presentaba "bajo el aspecto de un indolente egoísmo o de una estúpida indiferencia".

Toda estas tragedias están mal zurcidas, unidas ingenuamente, pero hay ojo avisor, inquietud social, apreciación objetiva. El I ideal clásico de escribir enseñando, que animara el siglo XVIII, se pierde en el exceso de palabras, en la excesiva elocuencia, en la falta absoluta de técnica novelística.

Puede hacerse una ligera presentación de las diversas fases que cabe estudiar en El Padre Horán con afán de investigar nuestra realidad.

Hay ante todo una dura crítica a la organizacion republicana. Se llega a poner en boca del Doctor Carmona aquella frase de que: "todo lo que es de España es bueno". Y que reafirma más adelante: "es preciso ser un imbécil para no afirmarlo". Se consideraba, así, que la situación del país era inferior a la época en que dependíamos de España a pesar de nuestro vasallaje. Pero por otro lado se subraya lachecesidad deana efectiva democracia, de establecer oel principiôn dè la iqualdgd „y el autor lo manifiesta en otra de sus páginas: "La igualdad, o más bien el deseo de igualdad, parece instintivo en la especie humana".

La obra muestra en todo momento la inconformidad del hombre del Perú en la primera mitad del siglo XIX. Se enjuicia, desde un punto de vista humano, la ineficacia de las guerras de la independencia que no establecieron un efectivo gobierno en beneficio del pueblo, como se proclamaba, y que por otra parte no solucionaron las más elementales necesidades de la población.

"Las viudas de los soldados no tienen montepío.

-Mi padre dijo... -exclamó con sentimiento Anjélica.

- A mi también: entonces pregunté, y me aseguraron que sólo las clases distinguidas de la milicia tenían derecho al montepío, porque para ello dejaban un tanto de sus haberes.

- ¿Con que las viudas de los valientes soldados que mueren en la guerra... privadas del apoyo que les presta- 
ran sus maridos... quizá el único que tenían para vivir ... están espuestas a perecer en la indijencia como tú... Casimira? -exclamó Anjélica con profundo dolor.

- Así es, señorita... Los que arrancan a los maridos de los brazos de sus mujeres, a los padres del lado de sus hijos... para llevarlos jayl al matadero, jamás han pensado en si las mujeres y los hijos de esos infelices... tienen asegurado un pan con que alimentarse... Haciéndolos servir a sus infernales designios, tratándolos con despotismo, con crueldad... $\mid \mathrm{oh} l \ldots$ esos impíos asesinos del jénero humano no han conseguido verlos muertos... los han abandonado acribillados de heridas... inútiles hasta para continuar. como antes proporcionándose la subsistencia con su industria... No hace mucho que murió un hermano mío, por quien todavía llevo este luto, después de una larga enfermedad adquirida en servicio de la patria...

La patria me quitó al padre de mis hijas - repuso con amargura - ipero la patria no se cura de la orfandad de las hijas, cuyos padres han vertido su sangre por ellal y menos de las que nacen en una cuna pobre, como la mía".

Los problemas sociales y jurídicos que afrontaba el Perú en los años de la Confederación y siguientes -y muchos de los cuales subsisten todavía- aparecen insertos en las páginas de $E l P a-$ dre Horán, libres, al parecer, de todo prejuicio personal y sólo como producto de una adecuada observación de la realidad. Veamos, por ejemplo, la siguiente cescena callejera gue nos presenta Aréstegui.

\section{"Jorge Puccinelli Converso"}

"-No progresamos en nuestro trabajo por falta de garantías...

- ¡Eh! ...dicen los de pescuezo colorado, que las leyes nos protejen... que se han hecho para nuestra felicidad. fensos.

- iSi! ... fabrican sus leyes sólo para oprimir a los inde-

- Y cuando ellos las quebrantan no les aplican la pena que merecen.

- iY dicen que todos somos iguales ante la ley!

- IEsa es una mentiral

- iCon esas palabritas nos han alusinado siempre!

- Y si alguna vez nos quejamos

... [Hum! ... nunca sacamos nadal

Como ellos hacen las leyes... las tuercen a su antojo...

$Y$ por contentarnos nos dicen " pbueno, buenol... ya lo veremos".

-Ellos tienen ojos, para ver lo que les conviene... no para hacerse cargo de nuestras necesidades. 
- ¿Esa es una verdad!

- ¿Pensarán que no estamos al cabo de todo?...

- "El populacho es ignorante"... dicen ellos... y se echan a dormir...

-Es porque pocas veces desplegamos los labios, para hacer presente lo mucho que se nos oprime...

-Guardamos silencio, porque estamos convencidos de que nuestras quejas nunca pasan los umbrales de Palacio.

-Y si llegan alguna vez allí... jlas sofocan!... jlas desprecianl...

- Solo Dios escucha las quejas del pobre...

-Y los de pescuezo colorado se hallan exentos de pagar contribuciones. ¡Y dicen que somos iguales ante la ley!

-No: ellos se jactan de pagar las contribuciones que llaman indirectas.

- Y entonces pagamos las personales.

- ¿No somos iguales ante la ley?

-Y para pagar esas contribuciones indirectas... ¿de qué cuero sacan las correas?

- ¡Del nuestro! jdel nuestro!

- iLa ocasión favorable!... vamos a despertar a esos que duermen tranquilos; y exijámosles una satisfacción por lo mal que nos tratan.

— ¡Ya se nos ha dicho! ..."el pueblo es soberano!... iresponsable solo ante si mismo!" blo! ...

- iSil jsi! ... iquien se atrevería a juzgar a todo un pue-

¡Que despierten los delpescuezonsolorado! ..."

Esta otra cita puede mostrarnos, asimismo, la insatisfacción que reinaba en el Perú en medio de la anarquía militar. Hay en ella una ahogada protesta, un llamado a la paz y a la feliz convivencia.

"-En las revoluciones quien pierde es el pueblo... No queremos sino la paz...

- Los que ganan son pocos...

- QQue se elevan a costa de nuestra sangre! ...y después son nuestros opresores.

- iTodo el que turba la paz, no quiere nuestra felicidad!

- ¡No queremos más revoluciones!...

- YYa se ha dicho! ... iquien pierde es el pueblo!

- iSi!... ciones.

- En cada revuelta nos aflijen con reclutajes y contribu- 
-Y nos encierran en la maestranza para que compongamos los fusiles, y hacer después que nos matemos los unos a los otros!"

El autor olvida a cada paso el relato de los acontecimientos para presentarnos el cuadro sombrío de la realidad peruana. Serían innumerables las citas que habría que consignar. Seguiremos el pensamiento del escritor a través de algunas de ellas que nos muestran la situación política del Perú, al ambiente social del elemento indígena y el estado ruinoso de nuestra industria y comercio.

'Lástima causaba ver la poca jente que desemboca 'en la plaza mayor por sus ocho boca-calles.

Diezmado el Cusco en las frecuentes guerras civiles por la enorme contribución de sus hijos, que reclutados sin distinción y convertidos en soldados van a presentar sus pechos en la primera acción de armas.. ¿cómo ro se convertirá en escombros?

Sin brazos ¿cómo progresará el único ramo de industria que le ha quedado para su consolación -la agricultura?...

Si no tienen consumidores, ¿para qué cultivarán todos sus terrenos los propietarios? De este modo no se volverá absolutamente improductivo ese infeliz departamento?...

Sus minerales vírgenes, sin explotarse por las mismas causas y por falta de espíritu de asociáción que es la fuerza motriz más eficaz para el engrandecimiento de un pueblo ¿cómo proporciónarán elementos para un comercio activo?...

Arrebatándose al trabajo numerosas muchedumbres para convertirlas en simples consumidores de lo producido por otros, en conservadoras del orden que solo ellas trastornan: en fuerza armada semejante a los abismos del mar que no devuelve lo que absorve... ¿no se atrasará la industria del país?

Los más fuertes han llegado al campo de la muerte, a ese espacio de terreno que pronto debía recibir sus ensangrentados cuerpos..., a ese panteón sin un sepulcro, sin una cruz, sin más muros quizá que las elevadas montañas coromadas de nieve.

¿Y acaso el vencedor ha combatido por la ventura nacional? Serán menos oprimidos los pueblos?... ¿recompensados los que derramaron sus sangres con la esperanza de ver a su patria feliz e independiente?

Restos que despedazan el corazón, es lo único que queda de ofrenda tan inútil: restos que no han bastado a aplacar ... la sed de sangre del monstruo de la revolución. 
...Los que han escapado de la muerte, inválidos ya para el trabajo, van a llevar a sus familias a un hombre más a quien alimentar.

Un país extenso y poco habitado como el nuestro sólo puede prosperar con la paz, y con una administración juiciosa y económica, que protejiendo la inmigración traiga a nuestras ciudades y a nuestros campos el saber, las industrias, y los brazos que nos faltan".

El sentimiento nativista, el espíritu serrano, cobran vida en la presentación del problema indígena. Dentro de esta. concepción de "indígena" cabe el elemento mestizo que puebla las ciudades, que forma el núcleo trabajador en cada una de ellas. La vida de Dionisio y Leandra -otra novela dentro de la novela generales en realidad la expresión clara y elocuente del problema. Los hijos de los indios son arrancados con frecuencia del hogar pobre para ser enviados en calidad de regalo, "como si fueran cerdos o perritos" dice el propio Dionisio cuando recuerda a su hijo Antolín. Y ellos - los padres-trabajan por dos reales, sin aliento en todo el día, bajo el grito amenazador o bajo el golpe brutal.

"Cargados tal vez de familia no tienen más esperanzas que sus brazos... Mientras que pueden hacer uso de ellos cuentan con dos reales diarios para su sustento...

¡Infelices! ...ni de esos dos reales somos dueños, porque de ellos tenemos todavía que pagar tributos... iOhl no sin razón envidio la suerte de los cuadrúpedos destinados a pasear a "sus amos por las calles de la" ciudad.

- ¡Tributos! ...jtributos!... -repitió Leandra con amargura. - Los que se llaman señores, se alimentan con nuestro sudor...

- Se sirven de nosotros como bestias de carga -interrumpió Dionisio - y cuando desplegamos los labios para quejarnos..."

Examina detenidamente el autor la legislación tributaria del campesino cusqueño.

"Poseen un hijo, que trabajando podía sostenar a sus ancianos padres; pero ya ese hijo, quizá muy joven todavía, está inscrito en la matrícula; paga tributos, por haber nacido de un padre que fue tributario, o que todavía lo es, y empieza a gastar sus fuerzas para alimentar con su sudor, como decía Leandra, a sus señores...

En el reparto de la porción del terreno de un distrito, los indios que pertenecen a él, llegan a optar un trecho de esca- 
sas varas cuadradas: nada más que el que su cacique le ha señalado. Además de las faenas a que se les obliga, como son el cultivo de las chacras del cacique, el de la pertenencia del alcalde, el de la Iglesia tal, la chacra señalada para dar culto al Santo cual; tiene que separar el quinceno.

Aun están sujetas a mil otras cargas, ya concejiles y que les quitan el tiempo aún para cultivar la porción que les cupo en el repartimiento, ya del momento como el servir con sus personas y animales si los tienen en el tránsito de tropas con peligro de la misma existencia. Sin garantías para no ser enrolados en el ejército, como ha sucedido en las revueltas políticas; casi siempre despotizados por los últimos mandones de su provincia: preguntamos restos infelices indios tributarios están suficientemente indemnizados con esa porción de terreno que trabajan para alimentarse éllos y sus hijos?

¿Y que diremos de esos indios tributarios, sin goce de tierras que se conocen con el nombre de forasteros?

¿Y de esos jóvenes indios, que aún antes de cumplir 18 años, ya pagan tributo con la denominación de próximos entrantes?

¡Y aún se abusa del sufrimiento de esta raza desgraciada! Apartando la vista de su indijencia, se les encarnece llamándolos felices, porque callan, sufren y obedecen, quizá por la fuerza, puesto que no pueden dejar de conocer cuando están verdaderamente obligados; y no se procura aliviar siquiera la triste suerte de sus hijos, mediante una mediana instrucción, suficiente lal levez para su ventura".

A través de las páginas de este libronestá, pues, el problema social del Perú. Allí está palpitando la "plebe" que un día consigue seis mil cuchillos no para saciar su hambre, sino para defender la milagrosa imagen del Señor de los Temblores, que se decía iba ser llevada a Bolivia y para destruir en su ignorancia la obra del escultor Arbe, cuyo crucifijo es destrozado por la multitud en una manifestación suigéneris mezclada de patriotismo anboliviano y de religión lugareña.

Aréstegui tiene algo del calor de Hugo en la defensa popular. Señala la falta del hospital; la falta de asistencia a las viudas y a los huérfanos; el problema de las cárceles donde el autor dice que "no se recobra la dignidad de si mismo".

"Otra falia grave y de funestas consecuencias se advierte en nuestra llamada cárcel - dijo Simeón desentendiéndose maliciosamente de las súplicas de don Tadeo-. Los más famosos criminales y los detenidos por culpas leves se 
hallan juntos en un mismo lugar; y lo más encandaloso es, que también los sujetos notables sean allí encerrados, bien por asuntos políticos, o bien porque no oblaron al instante la multa que se les exijió ...jOh!, y qué diremos de las frecuentes francachelas y borracheras que hay en la cácel, entre los criminales que ocupan el primer piso y las mujeres de igual calaña que ocupan el segundo piso?... Con sogas suben y bajan todo lo que sirve a sus comunes orjías... las mujeres cantan, tocan y bailan... Se embriagan miserablemente, riñen entre ellas, o se duermen rendidas del licor... El Alcaide grita, haciendo sonar su manojo de llaves... joh! ...Corramos un velo sobre estas repugnantes escenas..."

La crítica surge constante y permanente. Y se afana el autor en mostrar la necesidad de proteger nuestras industrias, de fomentar las manufacturas de tocuyos y de bayetas; de crear una riqueza nacional que Aréstegui mira sin embargo con escepticismo.

"Es muy rico el Perú ... pero jay! son muy pobres los peruanos".

No podía faltar el problema de la cultura y de los escritores. En algunas frases sueltas podemos encontrar este aspecto.

"- ¿En qué oficio supone U. ocupado a mi hijo?

- En el de escritor C considerándaló ya a la cabeza de un periódico de oposición después de haberse desgañitado ante un tribunal soñoliento defendiendo causas de oficio... sición?...

- ¿Y por qué cree U. que Wenceslao será escritor de opo-

- Porque en nuestro país es el único recurso de los afita atosigarnos, obras de toda clase... Nosotros, enclenques en principio ¿qué podemos producir que ya no se haya escrito estensamente?...

- Pero no es muy laudable para la familia del escritor, ni glorioso para él, ver por medio de su CONSAGRACION... la miseria en la casa, y el hombre fuera de ella...

- Es heroico sacrificarse por la patria... y la íntima satisfacción que de ello resulta, suficiente para consolarse de de cualesquiera persecuciones.

-Pero entre tanto, mi don Jorge, no puede U. alimentar a su familia con INTIMA SATISFACCION...

- Desgraciadamente cuando la materia de que estamos formados padece, sufre también mucho el espíritu.

-Parece que U. no conoce nuestro país -replicó don Bonifacio con una risa buliciosa -en fín... tengamos la espe- 
ranza de que quizá nuestros biznietos llegarán a ver en el Perú la literatura como una profesión..."

En cuanto a la presentación de costumbres, puede entresacarse de "El Padre Horán" muchos rasgos, fisonomías, modas de la época.

"Vestida Angélica con su traje azul y con su pañuelito ca fé prendido en el pecho, llevaba además un somberito de la China, un poco inclinado sobre la oreja derecha...

Uno de los presentes, como de trenticinco años, vestido de frac azul de paño, con el talle a media espalda y el cuello sobre la coronilla, fue el primero que tomó la palabra...

Desiertas estaban las calles y plazas: no había un farol encendido; parecía que el Cuzco dormía sosegadamente después de una fuerte pesadilla: sólo los serenos cantaban de vez en cuando el "Ave María" de estilo, haciendo oir en seguida el rápido sonido de sirinja del Dios de los Pastores...

- Hacie tiempo que no hay Congreso - dijo Calixto con aire pensativo- El estado economiza esos gastos; y los pueblos nada pierden con que no lo haya...

Una rasgada ventana baja, con vidrieras y rejas de fierro. daba paso a la luz, que se extendía sobre una mesa colocada a corta distancia y poblada de libras en cuarto-mayor, y de cuartones cuadrilongos con muestran de paño y casimir de algodón y de seda de vistoso matiz: todo lo cual daba a esta habitación uin aire mercantile

La puerta estaba entornada: varios cajones de pino de diferentes tamañosigmuchas cajas delcartóñy mucho papel de añafea arrojado aquí y allí, estrechando notablemente la vivienda impregnada del agradable olor que despide aquella madera".

La anécdota salta a cada momento en la lectura de "El Padre Horán". Ya es el pueblo del Cusco clamando por Gamarra y vociferando contra la Confederación Perú-Boliviana. Ya el recuerdo del cura desconocido que, sable mano en mano y a la cabeza de doce mil indios armados con palos, luchó contra las fuerzas de Santa Cruz en Yanacocha. Y se hace historia de las casas de las Compañías de Jesús, o del Convento de la Almudena; de los viejos claustros; de las celdas de las monjas, saturadas de aromas diversos y donde alrededor de la cuja dorada asomaban las sillas de baqueta y revoloteaban palomas blancas y gatos de piel parda. Callejuelas del Cusco con acequias y barro. Y para los penitentes: disciplinas de encerados ramales y juegos de cilicios, 
que pendían de los clavos introducidos en las hendiduras de las paredes de piedra labrada.

Formalmente, deja mucho que desear. Se nota la marcha forzada y el camino fácil de la cursilería declamatorici. Ya estaba el penacho en funciones. La grandilocuoneır. Pero, no puede dejas de apuntarse que el aulor se martiene discretamente entre bastidores y que sólo predica desde fuera, sin intervenir en la escena. Si el diálogo es pobre, no abusa en cambio de las descripciones. Se observa que le agrada el ruido de las gotas que se desprenden de las hojas del maíz y los pardos vapores de la tierra; así como mirar desde el valle a las nubes que "huyen como tropa de corderos perseguidos por un galgo". Habría ya el ideal romántico de la vuelta a la Naturaleza. Y Aréstegui, angustiado en la ciudad, internándose en el silencio de las plazas de la capital imperial, soñaba con la chacra jugosa, y con la cosecha a punto. Pero la quería para el dueño de ella, para el indígena.

El Padre Horán Vivió anatematizado por su realismo, por su cruda crítica y renació entre las páginas de las novelas de Clorinda Mattos, cusqueña como Aréstegui, y que recoge la tradición de aquél. Hay la misma defensa del elemento indígena, hay la misma pasión puesta en la persona de un cura lugareño. Es curioso advertir que en el año de 1836, el señor Manulal Torres Matio antepasado de la novelista citada dirigió ep su calidad de Prefecto del Cusco una cominatoria al Goberndalor Eclesiástico del Obispado por el asesinatogde Angela Bdrredav Mioivo central del ensayo novelístico de Aréstegui y antecedente indirecto de Aves sin Nido y de Indole. Tenemos pues que ir a El Padre Horán para iniciar el camino crítico del indigenismo peruano.

\section{APENDICE: DATOS BIOGRAFICOS DE NARCISO ARESTEGUI}

Narciso Aréstegui nació en el distrito de Huaro, a 120 kilómetros del Cuzco, en una fecha que debe estar comprendida entre 1815 y 1820 , pues según la partida de matrimonio - que Nello Marcos Sánchez D. inserta en su tesis, realizada dentro de las investigaciones de la Cátedra de Literatura Peruana General, en San Marcos- el citado autor se casó con doña María del Castillo en la capilla de Santa Rosa de la Iglesia del Sagrario de la Catedral del Cuzco el 26 de Diciembre de 1838. Imposible es pues aceptar la fecha de 1823 que se ha señalado en la misma investigación, pues no hay antecedentes en nuestro derecho eclesiástico o civil que autorice a suponer que pueda contraer- 
se enlace antes de los 18 años. Menos puede sostenerse la fecha dada anteriormente por los biógrafos de Aréstegui que traian su nacimiento a 1826. El simple dato registrado en su partida de defunción de haber fallecido a los 46 años no es certificación suficiente, pues seguramente fue hecha a base declaración de parientes o testigos, que no precisaron la auténtica edad de Aréstegui.

Se sabe que Aréstegui estudió en el Colegio Nacional de Ciencias y Artes, creado por Simón Bolívar, y que hizo estudios universitarios, graduándose de Abogado en el Colegio Seminario de San Antonio Abad, donde constan en los libros correspondientes, tanto los exámenes, como el grado final referido, que se realizó en 1852. Pero desde Febrero de 1850 era catedrático de Historia Antigua y Moderna y de Literatura, así como Secretario y Bibliotecario del Colegio Nacional de Ciencias.

Nello Marcos Sánchez, ha seguido también los pasos de su carrera militar. Se inicia ésta en los momentos de tirantez internacional con Bolivia, en 1853, incorporándose al batallón Guardia Nacional con el grado de Capitán. Rápidamente es ascendido a Sargento Mayor, y ya como Teniente Coronel forma parte del Ejército Revolucionario de Castilla en la batalla de La Palma, en la que su batallón "Cusco" tuvo actuación ponderable. Es Sub-prefecto del Cusco y luego Juez Militar de Primera Instancia del mismo Departamento; para participar más tarde en la batalla de Yumina, a las órdenes de San Román. La derrota de Vivanco en Arequipa y el éxito de Castilla, a cuyo Estado Mayor pertenece, le valen el grado de Coronel efectivo; destacando el citado estudiante, que en la misma Orden General obtienen su ascenso tres figuras importantes de nuestra historia: Mariano Ignacio Prado, Tomás Gutiérrez y Francisco Bolognesi. Renuncia públicamente a su condición de militar en 1864 por-las negociaciones del gobierno de Pezet con España y en la Dictadura de Prado es nombrado Rector del Colegio de Ciencias y Artes del Cuzco. En 1876 se le ve figurar como ViceDirector de la Sociedad Amiga de los Indios. En ese mismo año encabeza la revolución contra Prado en el Cuzco, uniéndose a Balta y a los Diez Canseco, en calidad de Prefecto y Comandante General del Departamento. El 10 de Setiembre de 1868 fue nombrado Prefecto de Puno, estando ya de Presidente el Coronel José Balta y siendo Ministro de Gobierno, don Pedro Gálvez.

Aréstegui murió el 9 de Febrero de 1869, ahogado en el Lago Titicaca.

En 1872 se publicaba en el Cuzco una novela suya póstuma, "El Angel Salvador", novela romántica muy inferior en originalidad y trama a "El Padre Horán", pero que alabara jubilosamente en el Prólogo Juan de Arona. 